\title{
Impacts of the Tropical Pacific/Indian Oceans on the Seasonal Cycle of the West African Monsoon
}

\author{
E. Mohino, ${ }^{*},+$ B. RodrígueZ-FonseCA,,${ }^{\#}$ C. R. Mechoso, ${ }^{\&}$ S. Gervois,* \\ P. RUTI,** AND F. CHAUVIN, ${ }^{++}$ \\ * LOCEAN/IPSL, Université Pierre et Marie Curie, Paris, France \\ ${ }^{+}$Universidad de Sevilla, Seville, Spain \\ \# Universidad Complutense de Madrid, Madrid, Spain \\ @ Instituto de Geosciencias, Consejo Superior de Investigaciones Cientificas and Universidad \\ Complutense de Madrid, Madrid, Spain \\ \& Department of Atmospheric and Oceanic Sciences, University of California, Los Angeles, \\ Los Angeles, California \\ ** Progetto Speciale Clima Globale, Ente Nazionale per le Nuove Tecnologie, \\ l'Energia e l'Ambiente, Rome, Italy \\ ${ }^{++}$GAME/CNRM, Météo-France/CNRS, Toulouse, France
}

(Manuscript received 9 August 2010, in final form 19 January 2011)

\begin{abstract}
The current consensus is that drought has developed in the Sahel during the second half of the twentieth century as a result of remote effects of oceanic anomalies amplified by local land-atmosphere interactions. This paper focuses on the impacts of oceanic anomalies upon West African climate and specifically aims to identify those from SST anomalies in the Pacific/Indian Oceans during spring and summer seasons, when they were significant. Idealized sensitivity experiments are performed with four atmospheric general circulation models (AGCMs). The prescribed SST patterns used in the AGCMs are based on the leading mode of covariability between SST anomalies over the Pacific/Indian Oceans and summer rainfall over West Africa. The results show that such oceanic anomalies in the Pacific/Indian Ocean lead to a northward shift of an anomalous dry belt from the Gulf of Guinea to the Sahel as the season advances. In the Sahel, the magnitude of rainfall anomalies is comparable to that obtained by other authors using SST anomalies confined to the proximity of the Atlantic Ocean. The mechanism connecting the Pacific/Indian SST anomalies with West African rainfall has a strong seasonal cycle. In spring (May and June), anomalous subsidence develops over both the Maritime Continent and the equatorial Atlantic in response to the enhanced equatorial heating. Precipitation increases over continental West Africa in association with stronger zonal convergence of moisture. In addition, precipitation decreases over the Gulf of Guinea. During the monsoon peak (July and August), the SST anomalies move westward over the equatorial Pacific and the two regions where subsidence occurred earlier in the seasons merge over West Africa. The monsoon weakens and rainfall decreases over the Sahel, especially in August.
\end{abstract}

\section{Introduction}

The Sahel is the region in West Africa ranging from $10^{\circ}$ to $18^{\circ} \mathrm{N}$. A prolonged drought developed in the region during the last three decades of the twentieth century. This drought, which was an outstanding climate anomaly event in recent history (Dai et al. 2004;

Corresponding author address: E. Mohino, LOCEAN/IPSL, Université Pierre et Marie Curie-Tour 45-55-4eme étage 4, place Jussieu, 75252 Paris CEDEX 05, France.

E-mail: emohino@fis.ucm.es
Trenberth et al. 2007), has been attributed to anomalies in surface conditions leading to desertification through positive land-atmosphere feedback processes (Charney 1975). Contributions from changes in surface hydrology (Nicholson 2000), radiative effects of desert dust aerosol (Yoshioka et al. 2007), and in vegetation cover (Zeng et al. 1999; Nicholson 2000) have also been suggested. Recent studies have identified sea surface temperature (SST) anomalies as the most important factor in influencing variability in Sahel rainfall during the late twentieth century (Folland et al. 1986; Palmer 1986; Rowell et al. 1992, 1995; Giannini et al. 2003; Mohino et al. 2011a). The 
current consensus is that drought developed in the Sahel during the second half of the twentieth century primarily in response to remote effects of SST anomalies amplified by local land-atmosphere interactions (Giannini et al. 2003).

SST variability in the tropical oceans has been recognized to be the main driver of rainfall variability in the Sahel at decadal time scales (Giannini et al. 2003). Folland et al. (1986), Lamb and Peppler (1992), Rowell et al. (1995), and more recently Yoshioka et al. (2007) and Hoerling et al. (2006) attributed a large part of Sahelian decadal precipitation changes to variations in the interhemispheric gradient of Atlantic SST anomalies. Bader and Latif (2003) suggested that drought in the Sahel could be connected to higher Indian Ocean SSTs. Caminade and Terray (2010) highlighted the importance of the Pacific basin in driving decadal drought in the Sahel.

Rainfall in the Sahel also has significant variations at interannual time scales. Several works have shown relationships between variability in Sahelian rainfall and variability in tropical Atlantic SST anomalies (Lamb and Peppler 1992; Camberlin et al. 2001; Ward 1998; Janicot et al. 1998; Paeth and Friederichs 2004; Losada et al. 2010). Losada et al. (2010) studied the impact of SST anomalies over the equatorial Atlantic upon rainfall variability over West Africa after the 1970s. They analyzed sensitivity experiments with atmospheric general circulation models (AGCMs) using prescribed idealized SST patterns restricted to the equatorial Atlantic and based on the main interannual mode of SST variability in the region (Zebiak 1993). In their experiments, warm SST anomalies result in positive rainfall anomalies over the Gulf of Guinea and negative ones over the Sahel. This rainfall dipole is then related to a southern shift of the intertropical convergence zone (ITCZ) and thus the monsoon flow. The reader is referred to RodriguezFonseca et al. (2010) for a further detailed review of rainfall response in West African rainfall to anomalous SSTs.

Other studies performed with observational and reanalysis datasets have shown negative correlations between anomalies in summer rainfall over the region and tropical Pacific SSTs (e.g., Folland et al. 1986; Rowell et al. 1995; Janicot et al. 1996, 1998; Ward 1998; Camberlin et al. 2001; Janicot et al. 2001; Giannini et al. 2003; Dai et al. 2004). AGCMs with prescribed SST anomalies have been shown to be capable of reproducing such a relationship (e.g., Palmer 1986; Palmer et al. 1992; Rowell et al. 1995; Janicot et al. 1998; Rowell 2001; Giannini et al. 2003; Moron et al. 2003, 2004; Paeth and Friederichs 2004). Several dynamical mechanisms have been proposed to explain the Sahel/Pacific teleconnection, including changes in the Walker circulation (Janicot et al. 1996, 1998), propagation of equatorial waves (Rowell 2001), and increased atmospheric vertical stability as well as reduced precipitation at the margins of convective regions due to a general warming of the tropical troposphere (Giannini et al. 2001; Neelin et al. 2003). The links between tropical Pacific SSTs and African rainfall have also been shown to vary with the season (Nicholson and Kim 1997; Camberlin et al. 2001).

Some studies have pointed out a change in this teleconnection behavior after the 1970s. Trzaska et al. (1996) and Janicot et al. $(1996,2001)$ suggested that the impact of El Niño-Southern Oscillation (ENSO) on Sahelian rainfall strengthened after the 1970s. The reasons for this change in behavior are not well understood even to this (present) day. Trzaska et al. argue that the decadal background may have modulated this relationship.

The main focus of the present study is to gain insight on whether and how SST anomalies in the Pacific/ Indian Ocean regions influence the rainfall seasonal cycle over the Sahel since the 1970s. Four state-of-the-art AGCMs are used to carry out the same idealized sensitivity experiments. This is relatively new and innovative, as most of the former published results only rely on a single AGCM set of experiments (e.g., Trzaska et al. 1996; Rowell 2001). The SST patterns used to drive the AGCMs are based on the leading mode of covariability between the time-varying anomalies in SST on the Pacific Ocean and in summer rainfall over West Africa during the period from 1979 to 2002 . We examine the different model sensitivities to the SST anomalies and the teleconnection mechanisms. First, section 2 provides details about the methodology and the employed datasets. Then, section 3 examines the main results based on the AGCM sensitivity experiments. Section 4 presents a discussion on the findings and the conclusions.

\section{Data and methodology}

\section{a. Observational datasets and models}

The employed rainfall dataset is based on the Climate Prediction Center (CPC) Merged Analysis of Precipitation (CMAP) (Xie and Arkin 1997) product. CMAP provides global, gridded, monthly-mean fields starting in 1979 with a horizontal resolution of $2.5^{\circ} \times 2.5^{\circ}$. The observed SST fields are based on the reconstructed Extended Reconstruction SST, version 2 (ERSST2), dataset (Smith and Reynolds 2004), which provides global, gridded, monthly-mean fields starting in 1854 with a horizontal resolution of $2^{\circ} \times 2^{\circ}$. To represent the observed large-scale flow in the tropics (velocity potential and streamfunction at lower and higher levels), we use 
TABLE 1. Description of the four models involved in the African Monsoon Multidisciplinary Analysis—Europe (AMMA-EU) sensitivity experiment.

\begin{tabular}{llcll}
\hline \hline \multicolumn{1}{c}{ Label } & \multicolumn{1}{c}{ AGCM } & Levels & Resolution (lon-lat) & Reference \\
\hline ARPEGE & ARPEGE, version 3 & 45 & T42, approx 2.80 $\times 2.80^{\circ}$ & Déqué et al. (1994) \\
ECHAM4 & ECHAM4 & 19 & T30, approx 3.75 $\times 3.71^{\circ}$ & Roeckner et al. (1996) \\
LMDZ & LMDZ4 & 19 & $3.75^{\circ} \times 2.50^{\circ}$ & Hourdin et al. (2006) \\
UCLA & UCLA 7.3 & 29 & $2.50^{\circ} \times 2.00^{\circ}$ & Mechoso et al. (2000) \\
\hline
\end{tabular}

the monthly-mean atmospheric reanalysis fields. As some studies pointed out biases in the reanalysis products over the tropics (Annamalai et al. 1999; Chan and Nigam 2009), we employed both the National Centers for Environmental Prediction-National Center for Atmospheric Research (NCEP-NCAR) reanalysis (Kalnay et al. 1996) and 40-yr European Centre for MediumRange Weather Forecasts Re-Analysis (ERA-40) (Uppala et al. 2005) products. The horizontal resolutions of these fields are $2.5^{\circ} \times 2.5^{\circ}$ and $1.125^{\circ} \times 1.125^{\circ}$, respectively.

Our study is carried out using the Action de Recherche Petite Echelle Grande Echelle (ARPEGE), ECHAM4, Laboratoire de Météorologie Dynamique Model with Zoom Capability (LMDZ), and University of California, Los Angeles (UCLA) AGCMs. The main characteristics and related references are shown in Table 1. Losada et al. (2010) showed that these models produce an acceptable simulation of the mean West African climate (see also section 3a). Each AGCM experiment consists of a 10member ensemble of simulations with prescribed initial conditions differing in small, random perturbations. As our interest is in the boreal summer, all simulations are run for the period 1 May-30 September.

\section{b. SST patterns and experiments}

The patterns of SST anomalies prescribed in our idealized AGCM sensitivity experiments are based on the leading mode of covariability between the anomalies in time-varying SST on the Pacific Ocean and in the summer rainfall over West Africa during the period 19792002. To obtain this leading mode, we first performed an extended maximum covariance analysis (EMCA) (Polo et al. 2008). The EMCA methodology is an extension of the maximum covariance analysis (MCA) [or singular value decomposition (SVD), see Bretherton et al. (1992) and Frankignoul and Kestenare (2005)], which considers more than one lag for the predictor variable, the anomalous detrended SST in our case. The EMCA was applied to the standardized June-September (JJAS) monthly anomalous rainfall using lags from -4 [February-May (FMAM)] to +3 [September-December (SOND)] for the SST anomalies. As in the classical MCA, each mode includes different spatial patterns (homogeneous and heterogeneous modes) and time series (expansion coefficients).
Readers are referred to Polo et al. (2008) and Mohino et al. (2011b) for further details about the EMCA methodology.

Next, we determined the years for which the absolute values of the mode's SST expansion coefficients were larger than one standard deviation of its time series. This procedure identified three years $(1983,1987,1997)$ for the warm phase (hereafter "warm years") and also three years $(1985,1988,1999)$ for the cold phase (hereafter "cold years"). Figures 1a-e represent one-half of the composite difference between the monthly-mean SSTs in the warm and cold years for the period May-September. Figure 1 shows large positive values over the eastern part of the Pacific basin and positive values along the western coast of North America and easternmost part of the extratropical North Pacific. There are also negative values in the western part of the basin, over the subtropical North Pacific and the tropical South Pacific, forming a horseshoelike pattern. The weak positive values in the western part of the Indian Ocean are consistent with the observed autocorrelation between SST anomalies in the equatorial eastern Pacific and western Indian Ocean (Reason et al. 2000). This could be related to a coupled atmosphere-ocean response to the Pacific warming (Zhong et al. 2005). The patterns in Fig. 1 also show hints of a time evolution. From May to September, the area of stronger warm SST anomalies in the equatorial Pacific shifts westward and the region of warm SST anomalies over the eastern and central Pacific extends in latitude. The area of cold anomalies in the western tropical Pacific expands in the northwestward direction. Moderate warm anomalies also develop over the northeastern Indian Ocean, peaking in June. Their evolution is consistent with the development of surface anomalous winds that would favor a warming of SSTs in spring and a cooling in summer (not shown). The SST anomaly fields to be superimposed on the ERSST2 climatology to provide the boundary conditions for our AGCMs are obtained by multiplying those shown in Fig. 1 by either +1 or -1 for the Pacific/Indian regions with zero values elsewhere. The +1 case will be referred to as the warm or positive experiment and the -1 as the cold or negative experiment. This procedure yields SST anomalies with realistic amplitudes. 

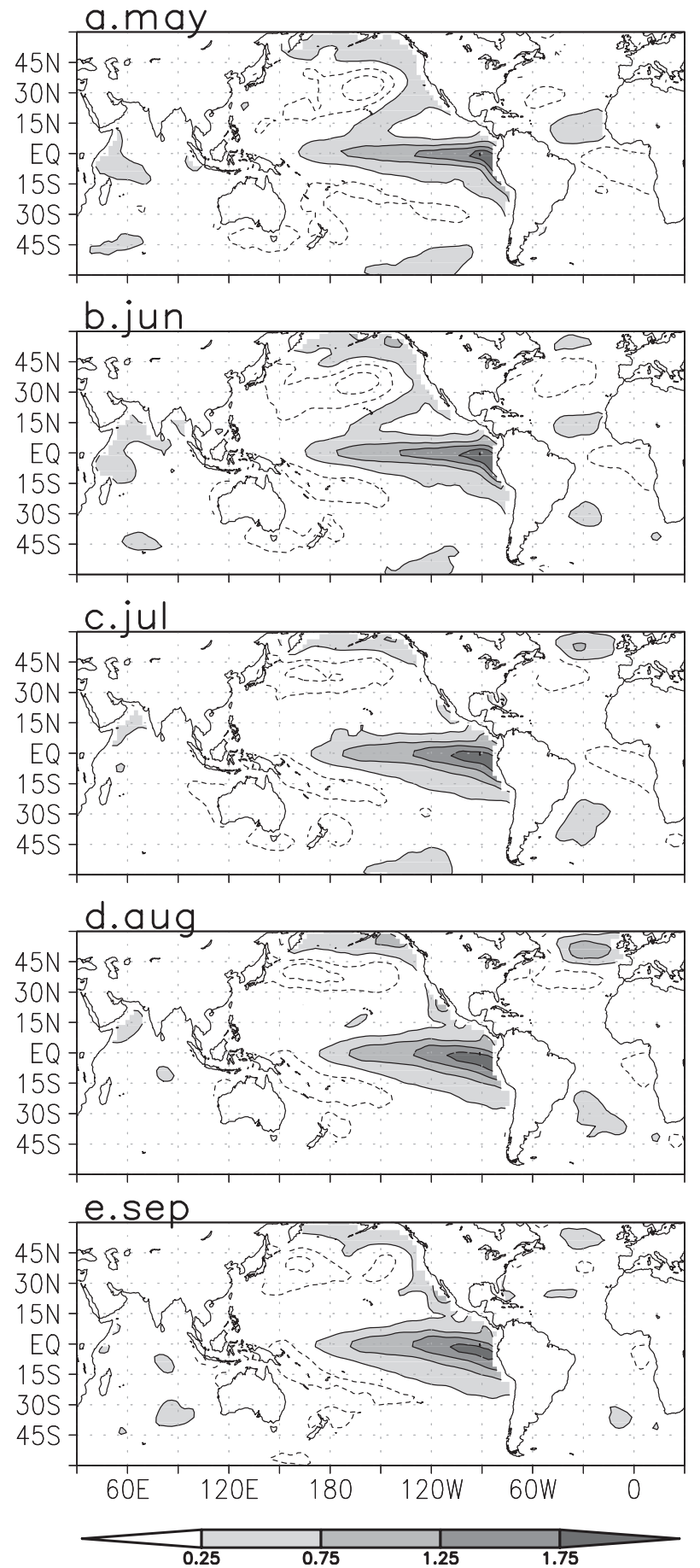

FIG. 1. Half the difference between the observed SST (K) composites averaged for the warm and cold years for (a) May, (b) June, (c) July, (d) August, and (e) September. Contours are plotted each $0.5 \mathrm{~K}$ starting from $0.25 \mathrm{~K}$. The zero contour plot is omitted; positive values are shaded.
Our AGCM experiments use a monthly evolving field of SST instead of a time-independent pattern (as in Trzaska et al. 1996) or a pattern with an idealized seasonal evolution (as in Rowell 2001). This provides a deeper insight into the timing of the teleconnections. The employed SST anomaly pattern is similar to the one used by Palmer et al. (1992) for the 1987-88 period. The magnitudes are also comparable to those used by Rowell (2001). From the west Pacific to the Indian Ocean, the SST gradient is oriented westward, as in the full experiment designed by Rowell (2001). However, the magnitude is weaker in our composite, as also are the SST anomalies over the Indian Ocean.

We highlight an important difference between the full SST patterns prescribed in our experiments and those conducted by Rowell (2001): the climatological fields correspond to different periods. Rowell used a climatology corresponding to the period 1961-90, while ours corresponds to the period 1979-2005. The latter climatology shows higher SSTs than the former in some locations, especially in the Southern Hemisphere and tropical eastern Pacific (Meehl et al. 2009). The difference between climatologies averaged over the tropics is $0.2 \mathrm{~K}$ and can be as large as $0.4 \mathrm{~K}$ at certain locations of the central equatorial Pacific or the eastern equatorial Atlantic. The warmer post-1970s context is considered to strengthen the teleconnection between the ENSO and Sahelian rainfall (Trzaska et al. 1996; Janicot et al. 1996, 2001).

Our analysis focuses on multimodel means so as to filter out the models' internal variability (Krishnamurti et al. 2000a,b). Prior to averaging, all model outputs were regridded to a horizontal resolution of $2.5^{\circ} \times 2.5^{\circ}$, which is common to the CMAP and NCEP-NCAR datasets. In the vertical, all model outputs were interpolated to 11 tropospheric levels ranging from 925 to $100 \mathrm{hPa}$. Following Meehl et al. (2007), we highlight the areas of high consistency among models, defined as those in which the multimodel ensemble mean is larger in magnitude than the intermodel standard deviation. For individual models, we test whether the response to the warm and cold simulations is significantly different by applying a two-sample $t$ test for equal means assuming equal variances.

For convenience, the observed differences during the warm and cold years and those between the warm and cold experiments will be referred to as observed and simulated anomalies, respectively.

\section{Results of the experiments}

\section{a. Simulated precipitation climatology}

Figure 2 compares the mean seasonal averages (for both spring and summer) of West African rainfall between 
a. OBS MJ

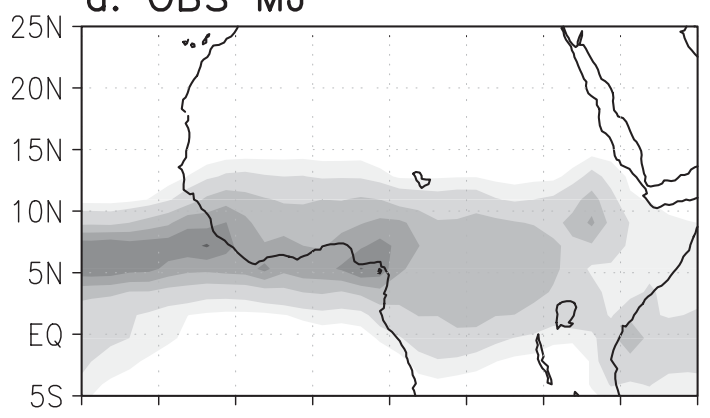

c. SIM MJ

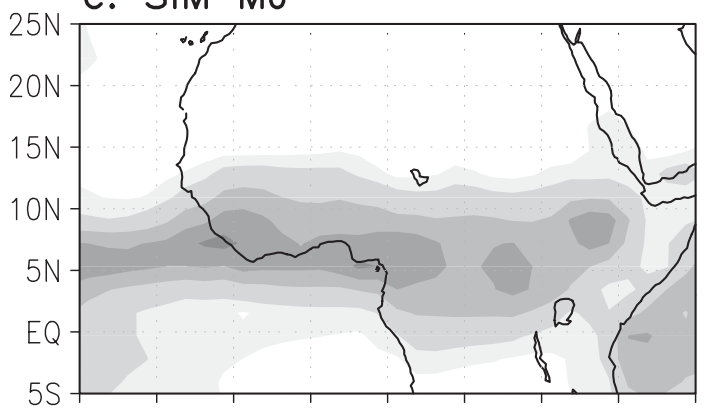

e. SIM-OBS MJ

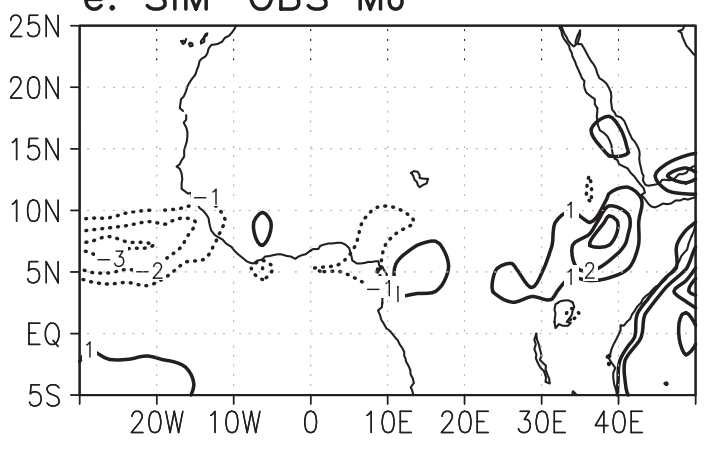

b. OBS JAS

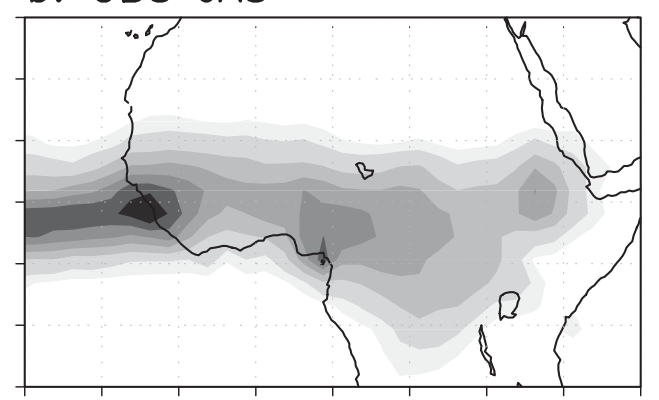

\section{d. SIM JAS}

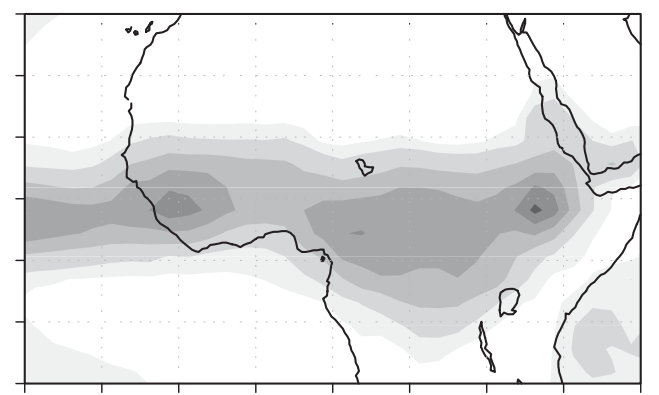

f. SIM-OBS JAS

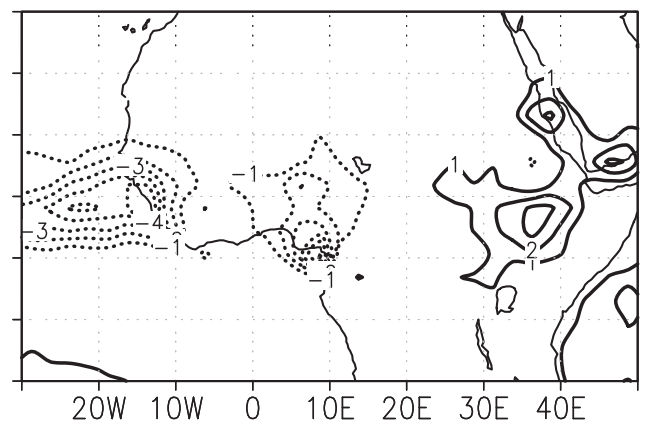

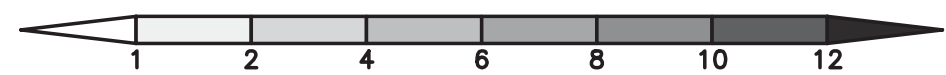

FIG. 2. Seasonal average of observed rainfall $\left(\mathrm{mm} \mathrm{day}^{-1}\right)$, using the CMAP dataset, for the period 1979-2005 for (a) the preonset (May and June) and (b) the monsoon peak (July-September). Multimodel seasonal average of rainfall response for the control run for (c) the preonset and (d) the monsoon peak. Differences between the multimodel ensemble and the observed rainfall for (e) the preonset and (f) the monsoon peak.

the observation and the control experiment. The corresponding patterns for each model can be found in Losada et al. (2010) and are further discussed in section 3d. The simulation correctly reproduces the latitudinal extension of the rainfall band over West Africa for both seasons. It also captures the latitudinal shift of the ITCZ that occurs from late spring to summer over the region (Fig. 2). In spring, and especially in summer, the simulation underestimates rainfall over oceanic areas such as offshore of Guinea and over Nigeria. Conversely, it overestimates rainfall over Ethiopia and underestimates it in the mountain regions of Cameroon and Guinea (Fig. 2).

\section{b. Precipitation anomalies over West Africa}

Figure 3 presents the differences between monthlymean observed precipitation during the warm and cold years together with those in the positive and negative experiments. During the preonset phase (May and June), the observations show positive (negative) anomalies north (south) of $5^{\circ} \mathrm{N}$ over the Atlantic Ocean. This dipole pattern is approximately opposite to the one obtained by Losada et al. (2010) with the same AGCMs and SST anomalies corresponding to the warm phase of the interannual observed equatorial Atlantic SST 


\section{a.may prec OBS}

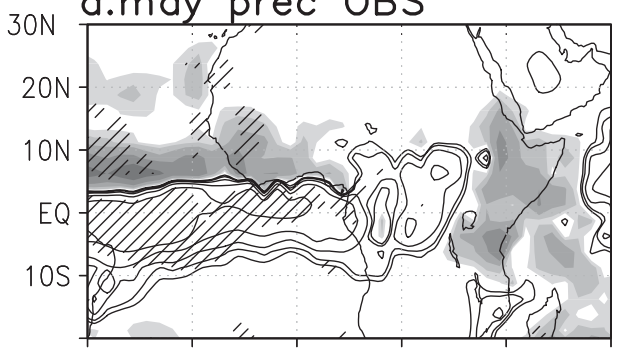

b.jun prec OBS

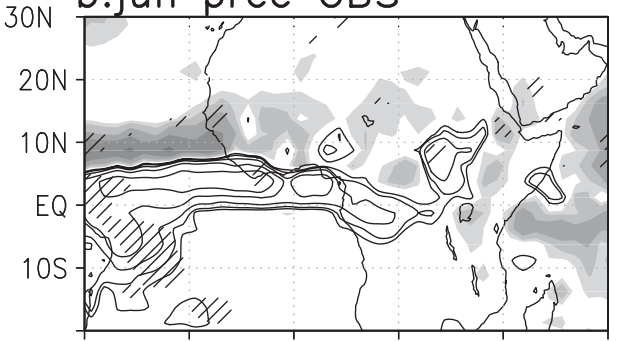

$30 N$

\section{c.jul prec OBS}

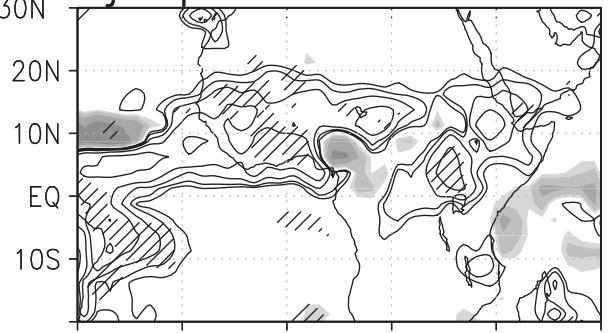

d.aug prec OBS
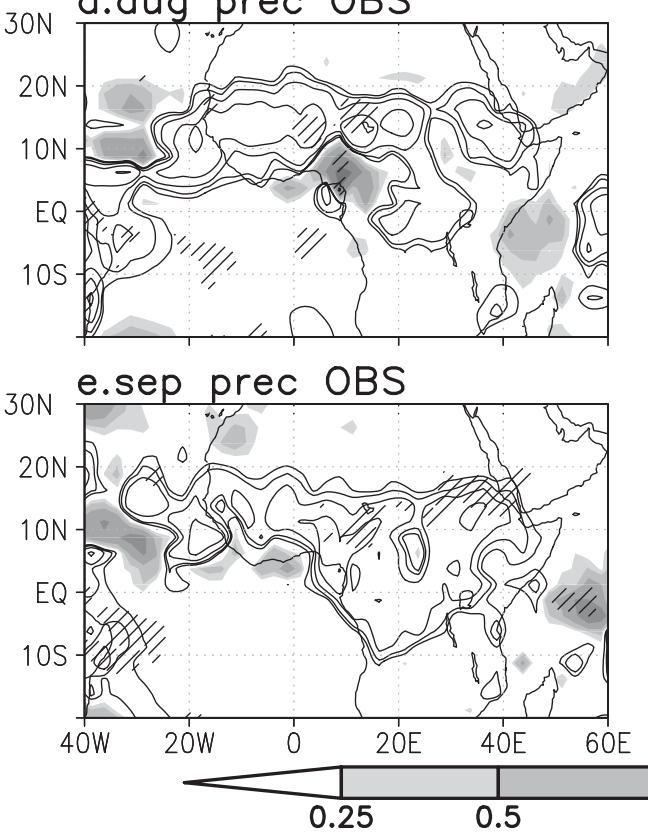

\section{f.may prec SIM}
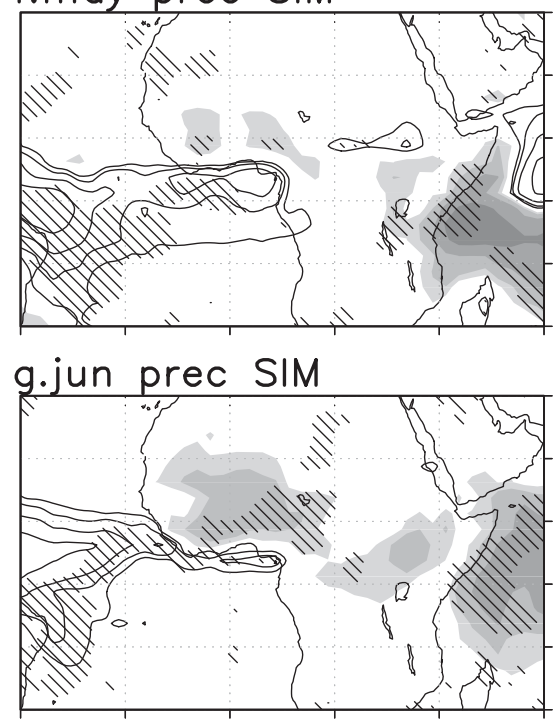

h.jul prec SIM
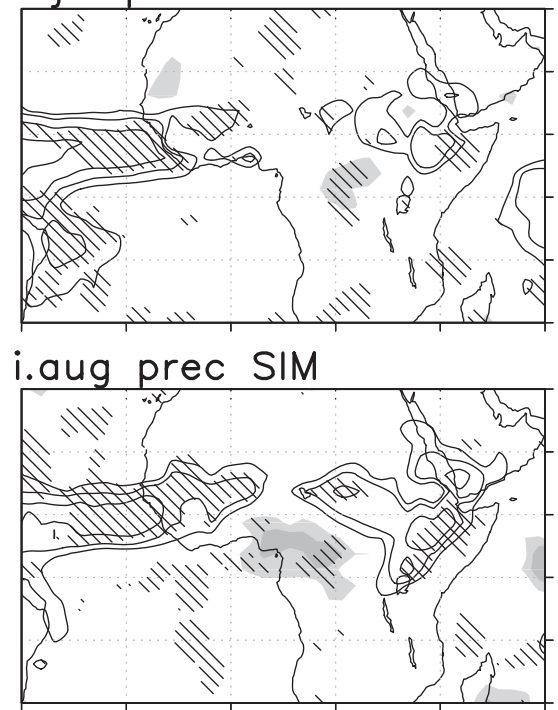

j.sep prec SIM

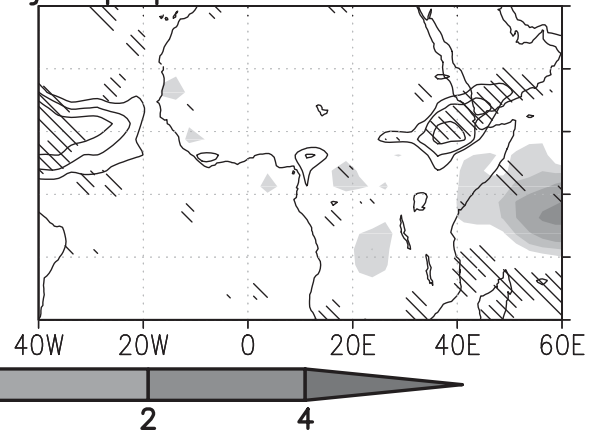

FIG. 3. Observed rainfall anomalies $\left(\mathrm{mm} \mathrm{day}^{-1}\right.$ ) for (a) May, (b) June, (c) July, (d) August, and (e) September. The right-tilted lines show the areas where the anomalies are statistically significant at $95 \%$ (according to a two-sample $t$ test for equal means assuming equal variances). (f)-(j) The simulated rainfall anomalies. The left-tilted lines show the areas where the multimodel ensemble mean is larger in magnitude than the intermodel standard deviation. Contours are plotted at $-0.25,-0.5,-1,-2$, and -4 ; positive values are shaded. 
mode. Rainfall increases over the western Sahel and decreases over the Gulf of Guinea. Rainfall also increases over eastern Africa in May. After the monsoon sets up, the pattern of rainfall differences changes. The monsoon onset (July) is marked by a latitudinal shift of rainfall deficits from the Gulf of Guinea to the Sahel, and the monsoon peak (August) presents fully developed negative anomalies over this region. Even though the warm minus cold composites were built with data for six events only, the rainfall deficits over the Gulf of Guinea in spring and over the Sahel in summer are statistically significant at $95 \%$ (Fig. 3). As the summer season ends (September), the negative anomalies over the Sahel weaken and rainfall deficits prevail over most of equatorial Africa (Fig. 3).

The simulation captures key aspects of anomalous rainfall from May to August. One of these aspects is the decreased precipitation over the Gulf of Guinea during May and June. This feature moves northward over West Africa in July and August, in association with a weakened monsoon strength (not shown). The simulation also captures the enhanced precipitation over the eastern coasts of Africa in May and the western equatorial Indian Ocean in June approximately above the concomitant positive SST anomalies (Fig. 1). The simulated rainfall anomalies, however, are weaker than those observed, especially over the Sahel.

There are clear nonlinearities in the response obtained in the warm and cold experiments. The simulated rainfall increase over the Sahel in spring is mainly related to the increase that occurs in the warm experiment (not shown). The simulated rainfall decrease over the Sahel in July is mainly due to enhanced rainfall in the cold experiment (not shown). Conversely, the simulation response in August is highly linear (not shown).

The most noticeable mismatch between precipitation anomalies in the observation and the simulation displayed in Fig. 3 is that the latter fields lack the positive rainfall anomalies in the tropical Atlantic sector north of $5^{\circ} \mathrm{N}$ from May to July. This point will be further discussed in section 4 .

\section{c. The tropical atmospheric response}

To gain insight into the underlying dynamics associated with the teleconnection between SST anomalies in the Pacific/Indian Oceans and the anomalous rainfall over West Africa, we examine the tropical atmospheric response in terms of the divergent and rotational components of the flow in the lower and upper troposphere ( 850 and $200 \mathrm{hPa}$, respectively). Figures 4 and 5 show the monthly-mean fields of velocity potential and divergent wind at the selected levels in the observation and the simulation. Similarly, Fig. 6 presents the eddy streamfunction at $200 \mathrm{hPa}$ for the observation and the simulation.

In spring, the simulation shows a center of convergence (divergence) at low (high) levels over the central and eastern equatorial Pacific (Figs. 4 and 5). Figure 6 shows a pair of anomalous anticyclones straddling the equator at $200 \mathrm{hPa}$ east of the date line. These features are consistent with the stationary equatorial Rossby wave response west of the main source of anomalous diabatic heating (Gill 1980), which is located over the eastern equatorial Pacific. A center of strong divergence (convergence) at low (high) levels occurs over Indonesia and the Philippines (Figs. 4 and 5). To the west of this center a pair of cyclones straddles the equator at $200 \mathrm{hPa}$. This feature is consistent with a Gill-Matsuno response to the anomalous cooling, which is associated with decreased convection (Matsuno 1966) (Fig. 6). There is another region of weak divergence (convergence) at low (high) levels over the Atlantic also accompanied by a pair of cyclones straddling the equator (Figs. 4-6). Another region of weak convergence at low levels and divergence at high levels appears over eastern Africa and the western Indian Ocean matching the warm SST anomalies in the Indian Ocean (Fig. 1). In the simulation for May, therefore, and more clearly for June, there is largescale subsidence over the Gulf of Guinea flanked in the zonal direction by centers of convergence (divergence) at low (high) levels. Over Africa in June, the simulation shows convergence (divergence) at low (high) levels. Consistently, in spring the simulation shows negative precipitation anomalies over the Gulf of Guinea (as in the observation) and positive rainfall anomalies over West Africa (albeit with a magnitude that is much weaker than in the observation).

In summer (July and August), the strong center of divergence (convergence) at low (high) levels over the Maritime Continent simulated in spring merges with the secondary one located over the Atlantic (Figs. 4 and 5). This simulated pattern change coincides with the weakening of the anomalous SSTs over the western Indian Ocean (Fig. 1). The two pairs of cyclones straddling the equator merge and only one pair remains centered over Africa in August in the simulation (Fig. 6). Note that this rotational response is different from the one presented by Rowell (2001), which consists of a quadrupole with twin anticyclones over East Africa and twin cyclones to the east. However, this feature is consistent with the weaker SST anomalies in the central Indian Ocean in our experiment (Fig. 1d) compared to those used by Rowell. According to this result, the anomalous diabatic heating over the Indian Ocean is not crucial for the establishment of links between warm tropical Pacific SSTs and reduced summer rainfall in the Sahel. The moderate 

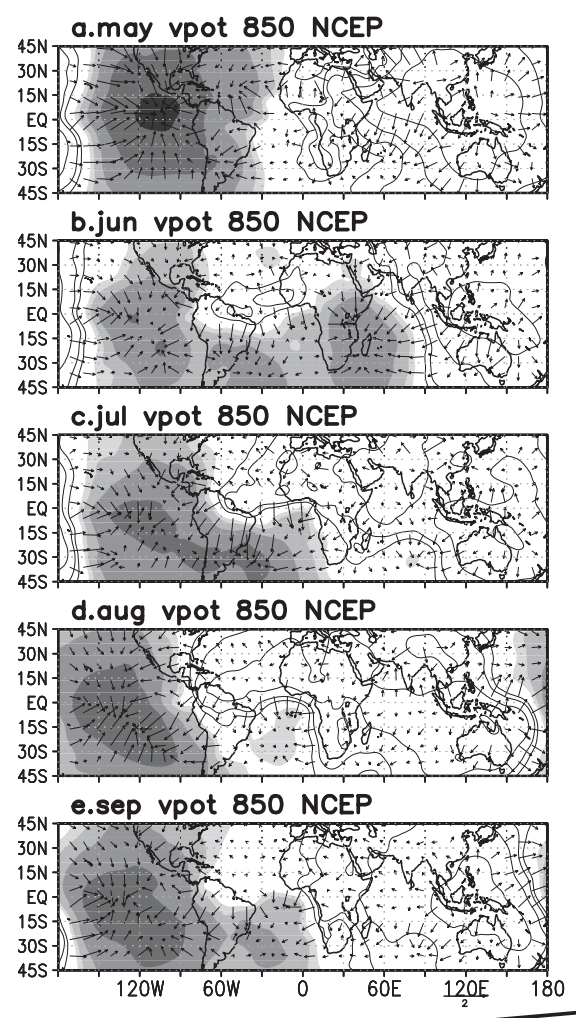
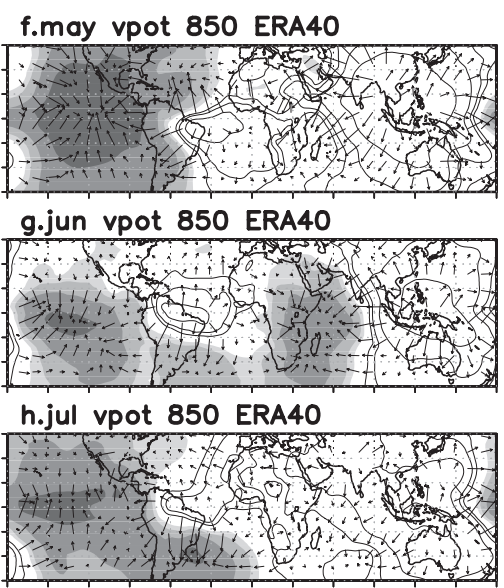

i.aug vpot 850 ERA40
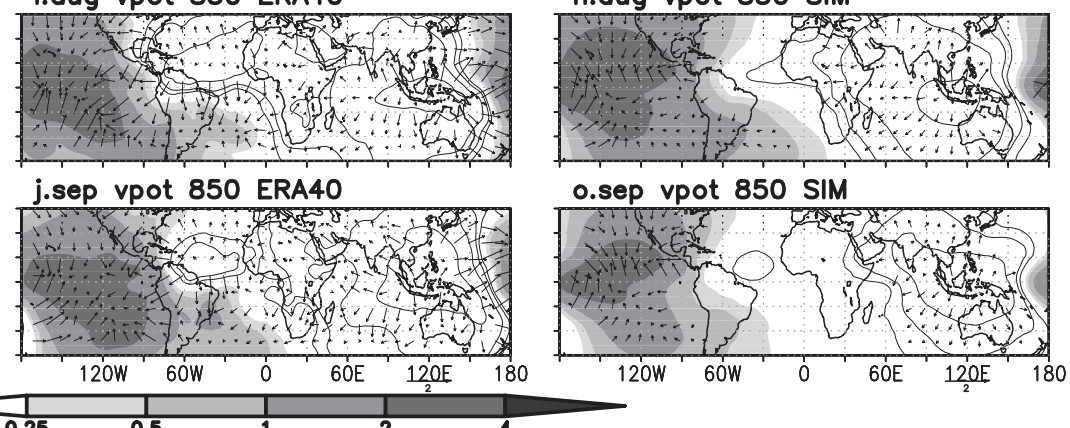

k.may vpot 850 SIM
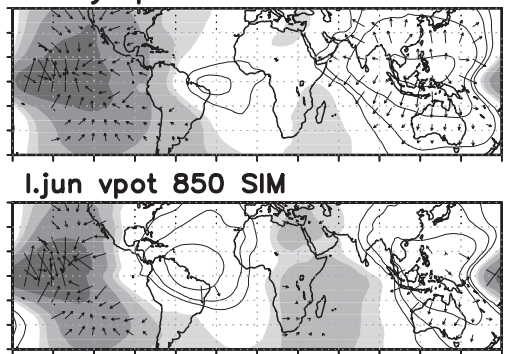

m.jul vpot 850 SIM

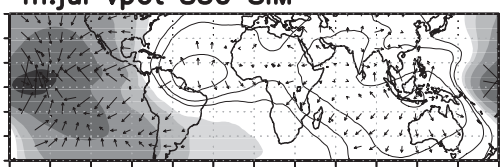

n.aug vpot 850 SIM

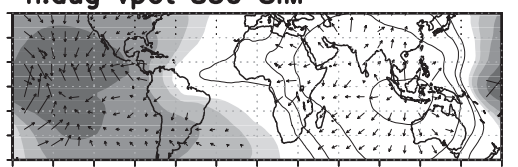

o.sep vpot 850 SIM

FIG. 4. Composite difference between warm and cold years of NCEP-NCAR reanalysis of velocity potential $\left(10^{6} \mathrm{~m}^{2} \mathrm{~s}^{-1}\right)$ and divergent wind ( $\mathrm{m} \mathrm{s}^{-1}$ ) at $850 \mathrm{hPa}$ (a) May, (b) June, (c) July, (d) August, and (e) September. (f)-(j) The same composite differences obtained with ERA-40. (k)-(o) Corresponding simulated anomalies for the same months. For the simulation, the divergent wind is only plotted in the areas where the multimodel ensemble mean is larger in magnitude than the intermodel standard deviation.

divergence at high levels over Africa and the western Indian Ocean in spring then disappears in summer. This happens when West Africa lies in a region of clear subsidence that weakens the monsoon strength and reduces precipitation.

The main characteristics of the simulated rotational and divergent anomalous flow are also observed in the composites (Figs. 4-6). There are, however, differences between the reanalysis and the simulated fields. For instance, the center of convergence at high levels over the Indian Ocean in summer does not extend as far west in the simulation as in the observation. Both reanalysis datasets show a similar structure in the rotational and divergent anomalous flow (Figs. 4-6). This structure is more complex than in the simulation, especially in August (Figs. 5 and 6). This is not unexpected since our AGCM experiments exclude the SST anomalies over the Atlantic Ocean. In addition, the ensemble averages over four models highlight the most consistent signal, smoothing out the fields.

The simulated anomalies weaken during the monsoon withdrawal (September) (Figs. 3-6). Though the results still include a relative convergence at high levels over Africa (Fig. 5), as in the observation, this is very weak and not accompanied by clear divergence at low levels (Fig. 4). Consistently, the simulation fails at reproducing the observed decrease in precipitation over West Africa.

\section{d. Sensitivity of the different models}

Most models reproduce the change from rainfall deficits over the Gulf of Guinea during the preonset to rainfall reductions over the Sahel during the peak of the monsoon season (Fig. 7). The precise location of those anomalies varies from one model to another. For instance, the decrease in Sahelian rainfall is simulated west (east) of $0^{\circ}$ for the ECHAM4 (ARPEGE) model (Fig. 7). In addition, not all models reproduce the same features. For instance, there is a continuation over the Atlantic Ocean of rainfall deficits in summer in all models except for the ARPEGE. Also, the increase of rainfall over the Sahel in spring is only produced by three out of the four models (Fig. 7). The anomalies shown by the different models over West Africa are weaker than those observed (Fig. 3 and 7), especially over the Sahel in summer. The reduction 
a.may vpot 200 NCEP

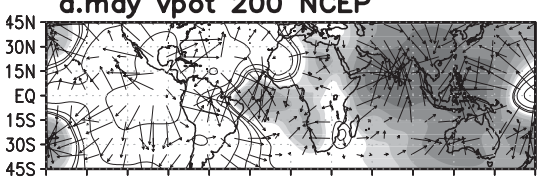

b.jun vpot 200 NCEP

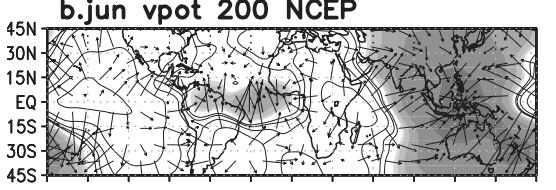

c.jul vpot 200 NCEP

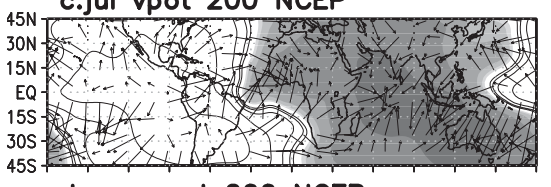

d.aug vpot 200 NCEP

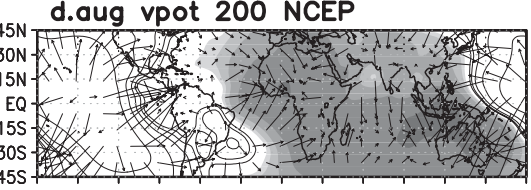

e.sep vpot 200 NCEP

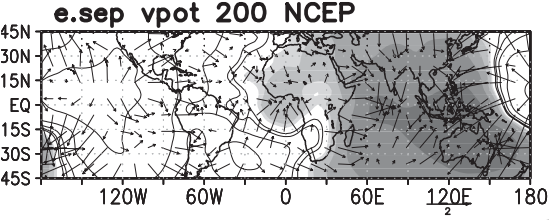

f.may vpot 200 ERA40

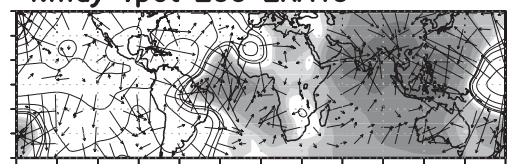

g.jun vpot 200 ERA40

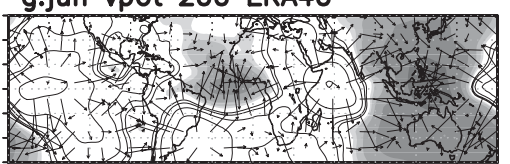

h.jul vpot 200 ERA40

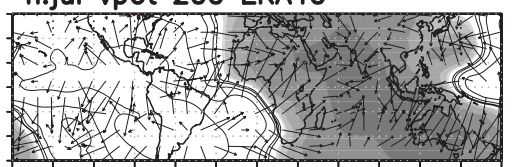

i.aug vpot 200 ERA40

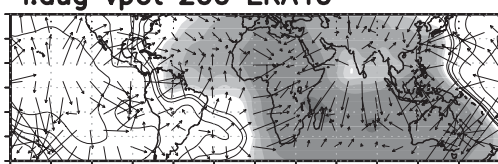

j.sep vpot 200 ERA40

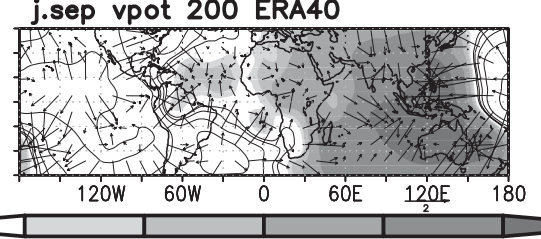

k.may vpot 200 SIM

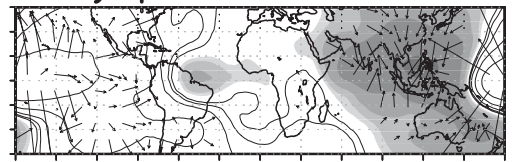

I.jun vpot 200 SIM

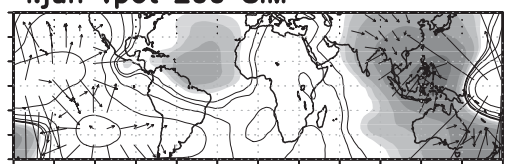

m.jul vpot 200 SIM

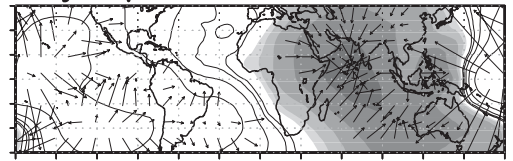

n.oug vpot 200 SIM

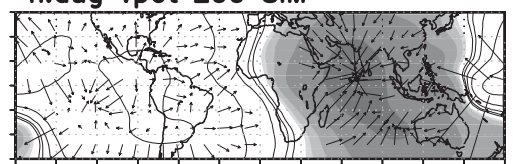

o.sep vpot $200 \mathrm{SIM}$

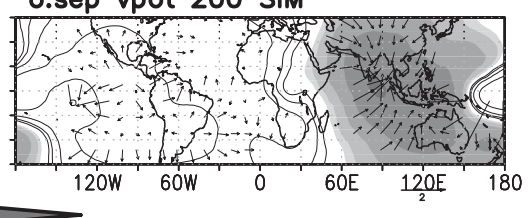

FIG. 5. As in Fig. 4 but for the velocity potential and divergent wind at $200 \mathrm{hPa}$.

in variability implied in the use of ensemble fields could explain part of the underestimation. Other factors related to the biases of the AGCMs, like the representation of land surface processes and the underestimation of associated feedbacks, could also contribute to this weakened response.

Figure 8 presents the rainfall signal-to-noise ratio (SN) for each model in spring [May and June (MJ)] and summer [July and August (JA)]. SN is defined as the ratio between the absolute value of the mean signal (the difference between the warm and cold simulations averaged over all ensemble members) and the intramodel standard deviation in the control run; that is, at each grid point,

$$
\mathrm{SN}=\frac{\left\|\frac{1}{N} \sum_{i=1}^{N}\left(x_{i}^{p}-x_{i}^{n}\right)\right\|}{\sqrt{\frac{1}{N-1} \sum_{i=1}^{N}\left(x_{i}^{c}-\bar{x}^{c}\right)^{2}}},
$$

where $N$ is the number of ensemble members ( $N=10$, in our case); $x_{i}^{p}, x_{i}^{n}$, and $x_{i}^{c}$ are the seasonal mean values [spring (MA) and summer (JA) in Fig. 8] of the ensemble member $i$ for the warm, cold, and control simulations, respectively; $\bar{x}^{c}$ is the seasonal mean value averaged over the $N$ ensembles of the control simulation:

$$
\bar{x}^{c}=\frac{1}{N} \sum_{i=1}^{N} x_{i}^{c} .
$$

The strongest $\mathrm{SN}$ values are obtained in the equatorial Pacific where the main SST anomalies lie (Fig. 8). Away from the forcing region the models depict areas of large SN values over the western equatorial Atlantic and northeastern Brazil and over the Maritime Continent. Most models show some areas of high values over North Africa, which extend into the Sahel and Guinea coast for the LMDZ and ECHAM4 models. The ARPEGE and ECHAM4 models also show high values over eastern Africa in summer. Qualitatively similar results are obtained using the normalized standard deviation as an estimate of the signal to noise ratio (Misra et al. 2003; not shown).

Regarding the large-scale flow, all models simulate the main centers of convergence and divergence at low levels over the equatorial Pacific east of the date line and over the Maritime Continent, respectively (Fig. 7). They also reproduce the centers of weak divergence 

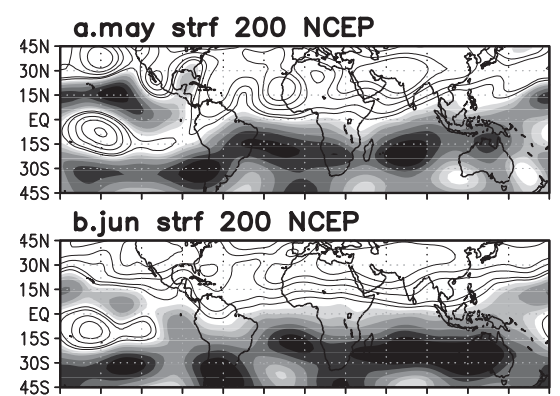

c.jul strf 200 NCEP
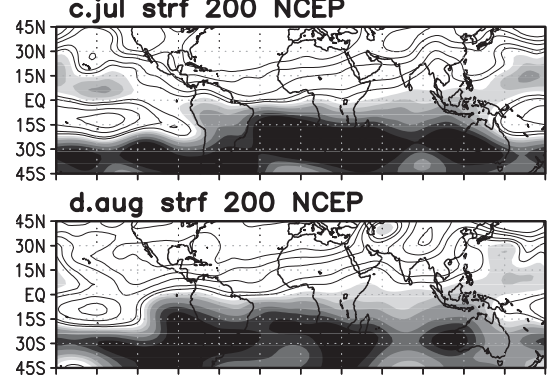

e.sep strf 200 NCEP

f.may strf 200 ERA40

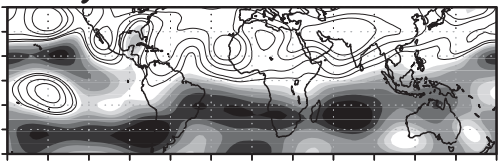

g.jun strf 200 ERA40

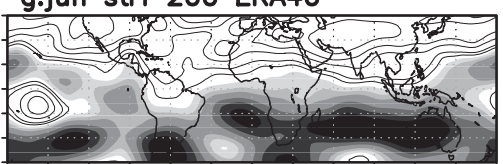

h.jul strf 200 ERA40
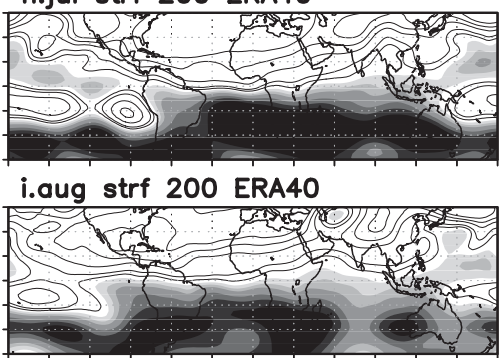

j.sep strf 200 ERA40

$30 \mathrm{~N}$

$15 \mathrm{~N}$
$\mathrm{EQ}$
$15 \mathrm{~S}$
$30 \mathrm{~S}$

$35 \mathrm{~S}$

$120 \mathrm{~W}$
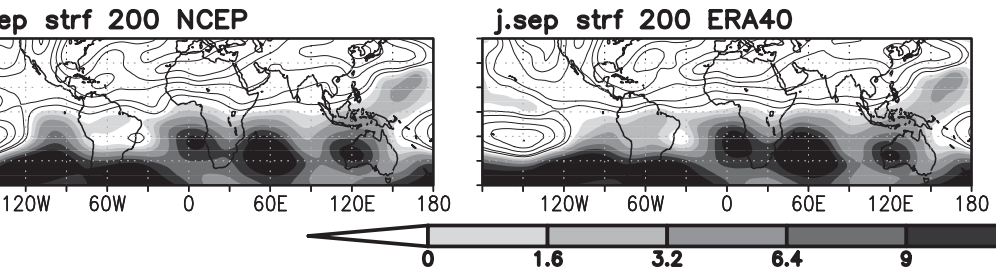

FIG. 6. As in Fig. 4 but for the eddy streamfunction at $200 \mathrm{hPa}$. Hatched lines in the simulation show the areas where the multimodel ensemble mean is larger in magnitude than the intermodel standard deviation.

and convergence at low levels in spring over the Atlantic Ocean and the western Indian Ocean, respectively (Fig. 7). The intensity and location of these centers is model dependent to some extent. For instance, the LMDZ model simulates weak divergence at low levels over the Atlantic Ocean, while the ECHAM4 model obtains strong divergence in the same region. In summer, the secondary center of convergence at low levels over the western Indian Ocean disappears, and the models simulate divergence at low levels over Africa, which is consistent with the reduced rainfall in the region (Fig. 7).

\section{Discussion and conclusions}

Previous works have established that SST anomalies in the Atlantic, Pacific, and Indian basins can all influence Sahel rainfall at different time scales. The objective of this study is to better understand the relationships between post-1970s tropical Pacific and Indian SST anomalies and West African rainfall at interannual time scales. In the post-1970s period, the relationships between Sahelian rainfall and Pacific SST anomalies have strengthened with respect to the previous decades (Janicot et al. 1996, 1998; Trzaska et al. 1996).
The years for which rainfall anomalies in the Sahel were connected to Pacific SST anomalies were identified by the application of a multivariate analysis method. Next, a composite of monthly-mean SST anomaly patterns was defined in the tropical Pacific/Indian Ocean only as one-half the difference between values corresponding to the warmest $(1983,1987,1997)$ and coldest $(1985,1988,1999)$ years. This composite was multiplied by either +1 or -1 and the result was superimposed on the SST climatology (1979-2005). The resulting SST patterns were then used as the boundary conditions to drive an ensemble of simulations with four different AGCMs (ARPEGE, ECHAM4, LMDZ, and UCLA). We contrasted the differences between observed fields in the warmest and coldest years, and the differences between the ensemble simulations referred to as positive and negative experiments.

Our results show that the influence of Pacific SST anomalies upon West African rainfall changes across the season. In late spring (May and June) West Africa lies between two regions of anomalous subsidence. The main region is located over the eastern Indian Ocean and the Maritime Continent, and the secondary one is over the central Atlantic. The multimodel ensemble mean shows 

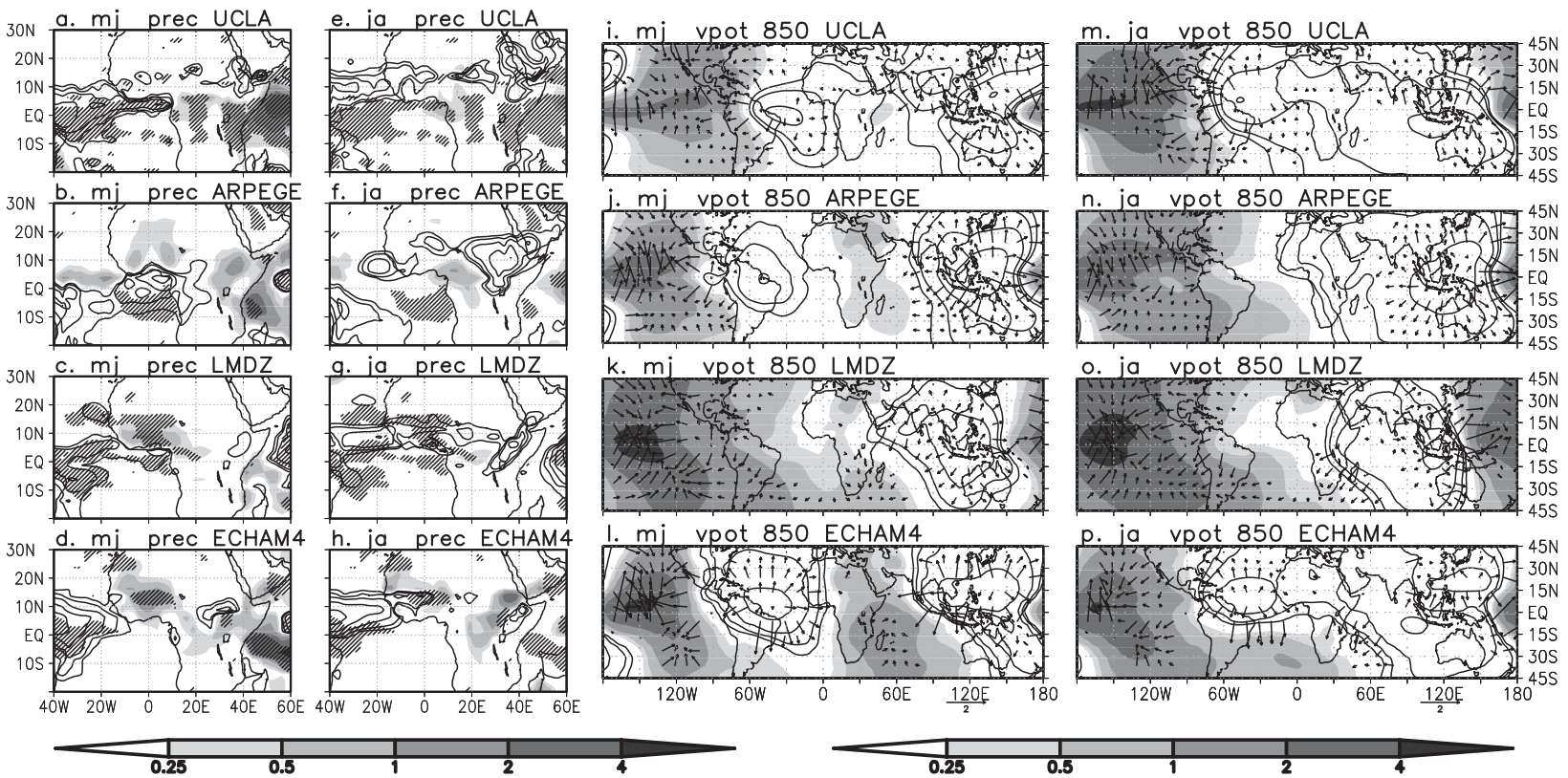

FIG. 7. Simulated rainfall anomalies $\left(\mathrm{mm} \mathrm{day}^{-1}\right.$ ) in spring (May-June) for the (a) UCLA, (b) ARPEGE, (c) LMDZ, and (d) ECHAM4 models. (e)-(h) The rainfall anomalies simulated in summer (July-August) for the same models. Spring (summer) anomalies of velocity potential $\left(10^{6} \mathrm{~m}^{2} \mathrm{~s}^{-1}\right)$ and divergent wind $\left(\mathrm{m} \mathrm{s}^{-1}\right)$ at $850 \mathrm{hPa}$ for the same models are shown in the third (fourth) column. The hatched lines show the areas where the simulated anomalies are statistically significant at the $95 \%$ confidence interval (according to a two-sample $t$ test for equal means assuming equal variances).

that increased rainfall over the Sahel in June is connected to enhanced divergence (convergence) at high (low) levels over West Africa.

During the monsoon peak (July and August) the two main centers of divergence (convergence) at low (high) levels merge. During this period, West Africa lies in a region of large subsidence (especially in August). This results in a weakening of the monsoon strength and thus a decrease of rainfall over the Sahel.

The change in the simulated anomalies across the seasonal cycle follows the change in location of the strongest SSTs anomalies. In spring the warm SST anomalies in the Pacific are confined to the easternmost central Pacific, and those over the western Indian Ocean have their maximum magnitudes. These features contribute to the establishment of the main tropical circulation with the primary center of convergence (divergence) at low (high) levels over the central-eastern Pacific basin and the secondary one over the western Indian Ocean. A region of relative subsidence is then located over the equatorial Atlantic, which leads to reduced rainfall over this basin and increased rainfall over the Sahel. During boreal summer, the SST anomalies in the Pacific Ocean extend westward and expand latitudinally, while the anomalies over the western Indian Ocean decrease in magnitude. This favors the merging of the two main centers of divergence (convergence) at low (high) levels, and the existence of a region of subsidence that covers the whole West African domain. This leads to reduced monsoon rainfall, especially over the Sahel. The simulated impact of SST anomalies on West African rainfall, therefore, can be described based on anomalies in the tropical circulation. This suggests that, though relatively strong, the cold SST anomalies over the central and western North Pacific have a negligible effect on West Africa.

However, there are significant differences between the simulations and the observations. As an example, the multimodel ensemble fails to capture the positive rainfall anomalies north of $5^{\circ} \mathrm{N}$ above the tropical Atlantic that are present in the observation for May and June. We do not expect a perfect match between observations and simulations since the experiment was driven with SST anomalies over the Pacific/Indian Oceans only. We note that during the period of study there were also weak negative (positive) anomalies of SST over the southeast (northeast) tropical Atlantic that are missing in the SST fields prescribed in our experiments. These SST anomalies in the Atlantic could explain the northward ITCZ shift that leads to the observed strong meridional dipole of rainfall anomalies over West Africa and the tropical Atlantic in spring. The SST anomalies in the Atlantic weaken in summer, and the response of the rainfall in the observation is mainly controlled by those 
a. $M J$ UCLA S/N

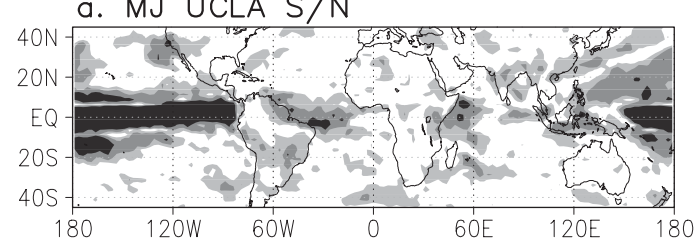

b. MJ ARPEGE $S / N$

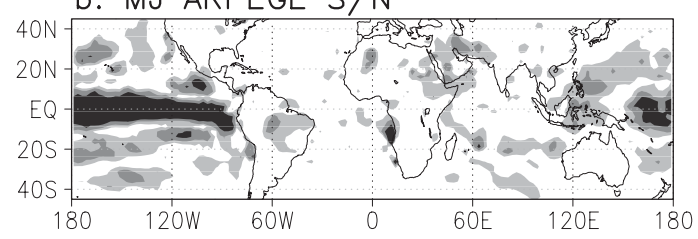

c. MJ LMDZ S/N

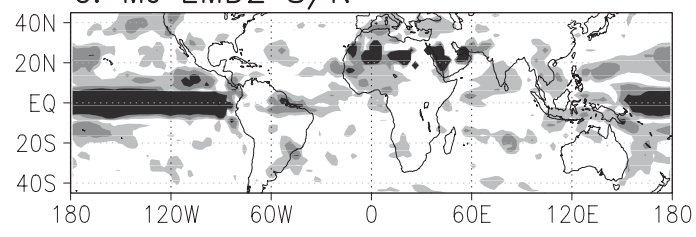

d. MJ ECHAM4 S/N

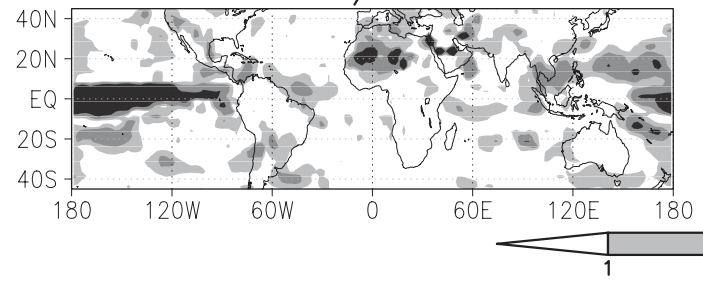

e. JA UCLA S/N

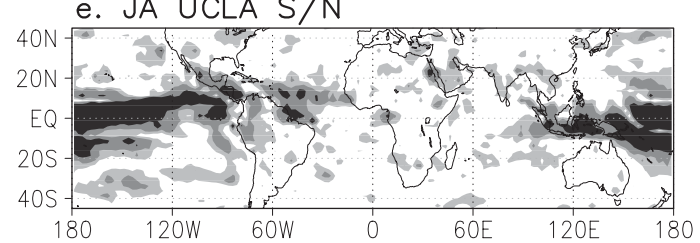

f. JA ARPEGE $S / N$

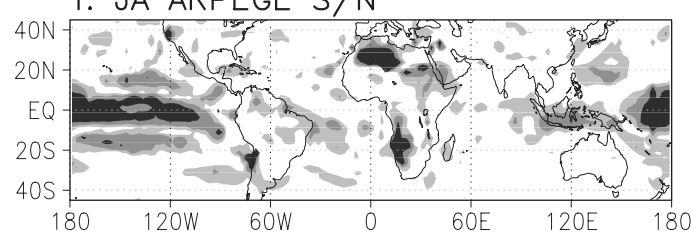

g. JA LMDZ S/N

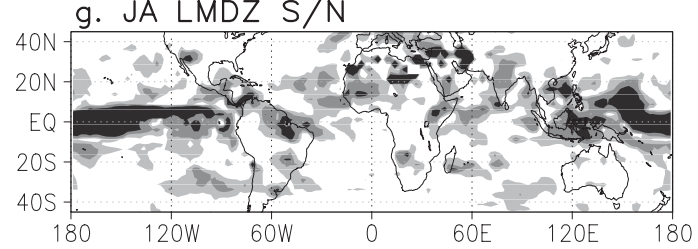

h. JA ECHAM4 S/N

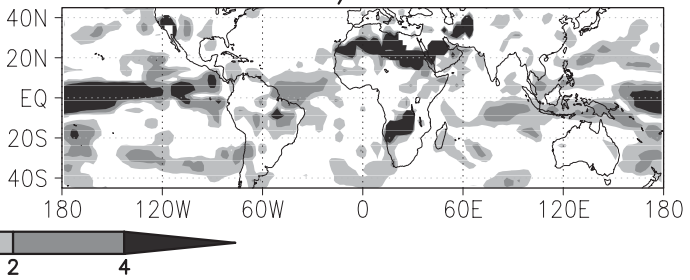

FIG. 8. Rainfall SN for each model in (left) spring (May-June) and (right) summer (July-August). This ratio is estimated as the quotient between the absolute value of the mean signal (the difference between the warm and cold simulations averaged over all ensemble members) and the intramodel standard deviation in the control run. See details in the text.

in the Pacific. For this reason, the simulated rainfall patterns resemble better those observed in summer than in spring.

We find differences in the response of individual AGCMs to the same SST patterns in their boundary conditions. Nevertheless, most of the models obtain the main features we have highlighted in the previous paragraphs. This adds confidence to the validity of our results.

Finally, we have found that SST anomalies in the Pacific/Indian basin after the 1970s can lead to interannual rainfall anomalies over the Sahel in summer of up to $1 \mathrm{~mm}$ day $^{-1}$ and with opposite signs; that is, warm anomalies correspond to drought. For the same period and with the same AGCMs, Losada et al. (2010) found that SST anomalies in the Atlantic basin can produce rainfall anomalies over the Sahel in summer of comparable magnitude and of opposite sign also; that is, warm anomalies correspond to drought again. It has also been shown that, after the 1970s, SST anomalies in the equatorial Atlantic and Pacific tend to have opposite signs (Rodriguez-Fonseca et al. 2009). If approximate linearity is accepted (Mechoso et al. 1990), then previous studies as well as the present one suggest that at interannual time scale Sahelian rainfall has been affected by SST anomalies in all ocean basins both before and after the 1970s. The combined overall effect of anomalies in different basins after the 1970s has led to a cancellation.

Acknowledgments. We thank the anonymous reviewers for their comments and suggestions that helped improve the manuscript. We are also grateful for the useful comments made by Javier Garcia-Serrano, Teresa Losada, and Irene Polo. This study was supported by the AMMAEU project. Based on a French initiative, AMMA was built by an international scientific group and is currently funded by a large number of agencies, especially from France, the United Kingdom, the United States, and Africa. AMMA has been the beneficiary of a major financial contribution from the European Community's Sixth Framework Research Programme. Detailed 
information on scientific coordination and funding is available on the AMMA International Web site (http:// www.amma-international.org). The first author is also grateful to the Complutense-Del Amo Grant Program and to the POSTDEXT-MEC Program of the Spanish Ministry of Science and Innovation. Additional support was provided by the Spanish Projects MEC CGL200910285 and MMA MOVAC:200800050084028. The GR58/ 08 Program (supported by BSCH and UCM) has also partially financed this work through the Research Group "Micrometeorology and Climate Variability" (910437).

\section{REFERENCES}

Annamalai, H., J. M. Slingo, K. R. Sperber, and K. Hodges, 1999: The mean evolution and variability of the Asian summer monsoon: Comparison of ECMWF and NCEP-NCAR reanalyses. Mon. Wea. Rev., 127, 1157-1186.

Bader, J., and M. Latif, 2003: The impact of decadal scale Indian Ocean SST anomalies on Sahelian rainfall and the North Atlantic Oscillation. Geophys. Res. Lett., 30, 2169, doi:10.1029/ 2003 GL018426.

Bretherton, C. S., C. Smith, and J. M. Wallace, 1992: An intercomparison of methods for finding coupled patterns in climate data. J. Climate, 5, 541-560.

Camberlin, P., S. Janicot, and I. Poccard, 2001: Seasonality and atmospheric dynamics of the teleconnection between African rainfall and tropical sea-surface temperature: Atlantic vs. ENSO. Int. J. Climatol., 21, 973-1005, doi:10.1002/joc.673.

Caminade, C., and L. Terray, 2010: Twentieth century Sahel rainfall variability as simulated by the ARPEGE AGCM, and future changes. Climate Dyn., 35, 75-94, doi:10.1007/s00382009-0545-4.

Chan, S. C., and S. Nigam, 2009: Residual diagnosis of diabatic heating from ERA-40 and NCEP reanalyses: Intercomparisons with TRMM. J. Climate, 22, 414-428.

Charney, J. G., 1975: Dynamics of deserts and drought in the Sahel. Quart. J. Roy. Meteor. Soc., 101, 193-202.

Dai, A., P. J. Lamb, K. E. Trenberth, M. Hulme, P. D. Jones, and P. Xie, 2004: The recent Sahel drought is real. Int. J. Climatol., 24, 1323-1331, doi:10.1002/joc.1083.

Déqué, M., C. Dreveton, A. Braun, and D. Cariolle, 1994: The ARPEGE/IFS atmosphere model: A contribution to the French community climate modeling. Climate Dyn., 10, 249-266.

Folland, C. K., T. N. Palmer, and D. E. Parker, 1986: Sahel rainfall and worldwide sea temperatures, 1901-85. Nature, 320, 602-607.

Frankignoul, C., and E. Kestenare, 2005: Observed Atlantic SST anomaly impact on the NAO: An update. J. Climate, 18, 40894094.

Giannini, A., J. C. H. Chiang, M. A. Cane, Y. Kushnir, and R. Seager, 2001: The ENSO teleconnection to the tropical Atlantic Ocean: Contributions of the remote and local SSTs to rainfall variability in the tropical Americas. J. Climate, 14, 4530-4544.

_- R. Saravannan, and P. Chang, 2003: Oceanic forcing of Sahel rainfall on interannual to interdecadal time scales. Science, 302, 1027-1030.

Gill, A. E., 1980: Some simple solutions for heat-induced tropical circulation. Quart. J. Roy. Meteor. Soc., 106, 447-462.
Hoerling, M., J. W. Hurrell, J. Eischeid, and A. S. Phillips, 2006: Detection and attribution of twentieth-century northern and southern African rainfall change. J. Climate, 19, 3989-4008.

Hourdin, F., and Coauthors, 2006: The LMDZ4 general circulation model: Climate performance and sensitivity to parametrized physics with emphasis on tropical convection. Climate Dyn., 27, 787-813.

Janicot, S., V. Moron, and B. Fontaine, 1996: ENSO dynamics and Sahel droughts. Geophys. Res. Lett., 23, 515-518.

_ A. Harzallah, B. Fontaine, and V. Moron, 1998: West African monsoon dynamics and eastern equatorial Atlantic and Pacific SST anomalies (1970-1988). J. Climate, 11, 1874-1882.

_ S. Trzaska, and I. Poccard, 2001: Summer Sahel-ENSO teleconnection and decadal time scale SST variations. Climate Dyn., 18, 303-320.

Kalnay, E., and Coauthors, 1996: The NCEP/NCAR 40-Year Reanalysis Project. Bull. Amer. Meteor. Soc., 77, 437-471.

Krishnamurti, T. N., C. M. Kishtawal, D. W. Shin, and C. E. Williford, 2000a: Improving tropical precipitation forecasts from a multianalysis superensemble. J. Climate, 13, 4217-4227.

— - — Z. Zhang, T. LaRow, D. Bachiochi, E. Williford, S. Gadgil, and S. Surendran, 2000b: Multimodel ensemble forecasts for weather and seasonal climate. J. Climate, 13, 4196-4216.

Lamb, P. J., and R. A. Peppler, 1992: Further case studies of tropical Atlantic surface atmospheric and oceanic patterns associated with sub-Saharan drought. J. Climate, 5, 476-488.

Losada, T., B. Rodriguez-Fonseca, S. Janicot, S. Gervois, F. Chauvin, and P. Ruti, 2010: A multi-model approach to the Atlantic Equatorial mode. Impact on the West African monsoon. Climate Dyn., 35, 29-43.

Matsuno, T., 1966: Quasigeostrophic motions in the equatorial area. J. Meteor. Soc. Japan, 44, 25-42.

Mechoso, C. R., S. W. Lyons, and J. A. Spahr, 1990: The impact of sea surface temperature anomalies on the rainfall over northeast Brazil. J. Climate, 3, 812-826.

— J. Y. Yu, and A. Arakawa, 2000: A coupled GCM pilgrimage: From climate catastrophe to ENSO simulations. General Circulation Model Development, D. A. Randall, Ed., International Geophysics Series, Vol. 70, Academic Press, 539-575.

Meehl, G. A., and Coauthors, 2007: Global climate projections. Climate Change 2007: The Physical Science Basis, S. Solomon et al., Eds., Cambridge University Press, 747-845.

— A. Hu, and B. D. Santer, 2009: The mid-1970s climate shift in the Pacific and the relative roles of forced versus inherent decadal variability. J. Climate, 22, 780-792.

Misra, V., P. A. Dirmeyer, and B. P. Kirtman, 2003: Dynamic downscaling of seasonal simulations over South America. J. Climate, 16, 103-117.

Mohino, E., S. Janicot, and J. Bader, 2011a: Sahel rainfall and decadal to multi-decadal sea surface temperature variability. Climate Dyn., doi:10.1007/s00382-010-0867-2, in press.

_ B. Rodriguez-Fonseca, T. Losada, S. Gervois, S. Janicot, J. Bader, P. Ruti, and F. Chauvin, 2011b: Changes in the interannual SST-forced signals on West African rainfall: AGCM intercomparison. Climate Dyn., in press.

Moron, V., N. Philippon, and B. Fontaine, 2003: Skill of Sahel rainfall variability in four atmospheric GCMs forced by prescribed SST. Geophys. Res. Lett., 30, 2221, doi:10.1029/ 2003 GL018006.

- — - and - 2004: Simulation of West African monsoon circulation in four atmospheric general circulation models forced by prescribed sea surface temperature. J. Geophys. Res., 109, D24105, doi:10.1029/2004JD004760. 
Neelin, J. D., C. Chou, and H. Su, 2003: Tropical drought regions in global warming and El Niño teleconnections. Geophys. Res. Lett., 30, 2275, doi:10.1029/2003GL018625.

Nicholson, S. E., 2000: Land surface processes and Sahel climate. Rev. Geophys., 38, 117-139.

_ Oscillation to African rainfall. Int. J. Climate, 17, 117-135.

Paeth, H., and P. Friederichs, 2004: Seasonality and time scales in the relationship between global SST and African rainfall. Climate Dyn., 23, 815-837.

Palmer, T. N., 1986: Influence of the Atlantic, Pacific, and Indian Oceans on Sahel rainfall. Nature, 322, 251-253.

_ C. C. Branković, P. Viterbo, and J. Miller, 1992: Modeling interannual variations of summer monsoons. J. Climate, $\mathbf{5}$, 399-417.

Polo, I., B. Rodríguez-Fonseca, T. Losada, and J. García-Serrano, 2008: Tropical Atlantic variability modes (1979-2001). Part I: Time-evolving SST models related to West African rainfall. J. Climate, 21, 6457-6475.

Reason, C. J. C., R. J. Allan, J. A. Lindesay, and T. J. Ansell, 2000: ENSO and climatic signals across the Indian Ocean basin in the global context: Part I, interannual composite patterns. Int. J. Climatol., 20, 1285-1327.

Rodriguez-Fonseca, B., I. Polo, J. Garcia-Serrano, L. Losada E. Mohino, C. R. Mechoso, and F. Kucharski, 2009: Is the Atlantic Niño dynamically affecting the Pacific ENSO in recent decades? Geophys. Res. Lett., 36, L20705, doi:10.1029/ 2009GL040048.

— , and Coauthors, 2010: Interannual and decadal SST-forced responses of the West African monsoon. Atmos. Sci. Lett., 12, 67-74, doi:10.1002/asl.308.

Roeckner, E., and Coauthors, 1996: The atmospheric general circulation model ECHAM-4: Model description and simulation of present-day climate. Max-Planck Institute for Meteorology Rep. 218, 94 pp.

Rowell, D. P., 2001: Teleconnections between the tropical Pacific and the Sahel. Quart. J. Roy. Meteor. Soc., 127, 1683-1706.

, C. K. Folland, K. Maskell, J. A. Owen, and N. M. Ward, 1992: Modelling the influence of global sea surface temperatures on the variability and predictability of seasonal Sahel rainfall. Geophys. Res. Lett., 19, 905-908.

_ $-\longrightarrow$, , and N. M. Ward, 1995: Variability of summer rainfall over tropical north Africa (1906-92): Observations and modelling. Quart. J. Roy. Meteor. Soc., 121, 669-704.

Smith, T. M., and R. W. Reynolds, 2004: Improved extended reconstruction of SST (1854-1997). J. Climate, 17, 24662477.

Trenberth, K. E., and Coauthors, 2007: Observations: Surface and atmospheric climate change. Climate Change 2007: The Physical Science Basis, S. Solomon et al., Eds., Cambridge University Press, 235-336.

Trzaska, S., V. Moron, and B. Fontaine, 1996: Global atmospheric response to specific linear combinations of the main SST modes. Part I: Numerical experiments and preliminary results. Ann. Geophys., 14, 1066-1077.

Uppala, S. M., and Coauthors, 2005: The ERA-40 Re-Analysis. Quart. J. Roy. Meteor. Soc., 131, 2961-3012.

Ward, M. N., 1998: Diagnosis and short-lead time prediction of summer rainfall in tropical North Africa at interannual and multidecadal time scales. J. Climate, 11, 3167-3191.

Xie, P., and P. A. Arkin, 1997: Global precipitation: A 17-year monthly analysis based on gauge observations, satellite estimates, and numerical model outputs. Bull. Amer. Meteor. Soc., 78, 2539-2558.

Yoshioka, M., N. M. Mahowald, A. J. Conley, W. D. Collins, D. W. Fillmore, C. S. Zender, and D. B. Coleman, 2007: Impact of desert dust radiative forcing on Sahel precipitation: Relative importance of dust compared to sea surface temperature variations, vegetation changes, and greenhouse gas warming. J. Climate, 20, 1445-1467.

Zebiak, S. E., 1993: Air-sea interaction in the equatorial Atlantic region. J. Climate, 6, 1567-1586.

Zeng, N., J. D. Neelin, K. M. Lau, and C. J. Tucker, 1999: Enhancement of interdecadal climate variability in the Sahel by vegetation interaction. Science, 286, 1537-1540.

Zhong, A., H. H. Hendon, and O. Alves, 2005: Indian Ocean variability and its association with ENSO in a global coupled model. J. Climate, 18, 3634-3649. 
Copyright of Journal of Climate is the property of American Meteorological Society and its content may not be copied or emailed to multiple sites or posted to a listserv without the copyright holder's express written permission. However, users may print, download, or email articles for individual use. 